\title{
Start in molekulare Welten
}

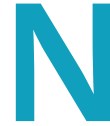

achdem bereits in Ausgabe 4 der Geburtstag von Herrn Prof. Dr. Schultze-Werninghaus als Mitbegründer dieses Journals Anlass zu Glückwünschen war, gilt der gleiche Anlass in dieser Ausgabe für einen weiteren Mitbegründer des Allergo Journal, Herrn Prof. Dr. Dr. Johannes Ring. Ab Seite 376 lassen wir seine herausragenden Leistungen für die Allergologie Revue passieren.

Im Fortbildungsteil steht der Hauttest als Prick- bzw. Intrakutan- oder Reibtest im Mittelpunkt. Er ist die traditionellste Form, Ursachen allergischer Erkrankungen nachzuweisen. Eine neue Leitlinie beschreibt ab Seite 402 Durchführung und aktuellen Stellenwert in der allergologischen Diagnostik. Obgleich eine komponentenbasierte Allergiediagnostik auch mittels Hauttest denkbar wäre, hat diese Diagnostikform bislang nur in der In-vitro-Diagnostik schon praktische Anwendung gefunden.

Die sich hier ergebenden Möglichkeiten basieren auf Ergebnissen der molekularen Allergologie, zu deren besserem Verständnis eine neue Serie im Allergo Journal beitragen soll. Diese Ausgabe markiert den Auftakt: Ab Seite 390 bieten Ihnen Jörg Kleine-Tebbe, Markus Ollert und Thilo Jakob im ersten Teil

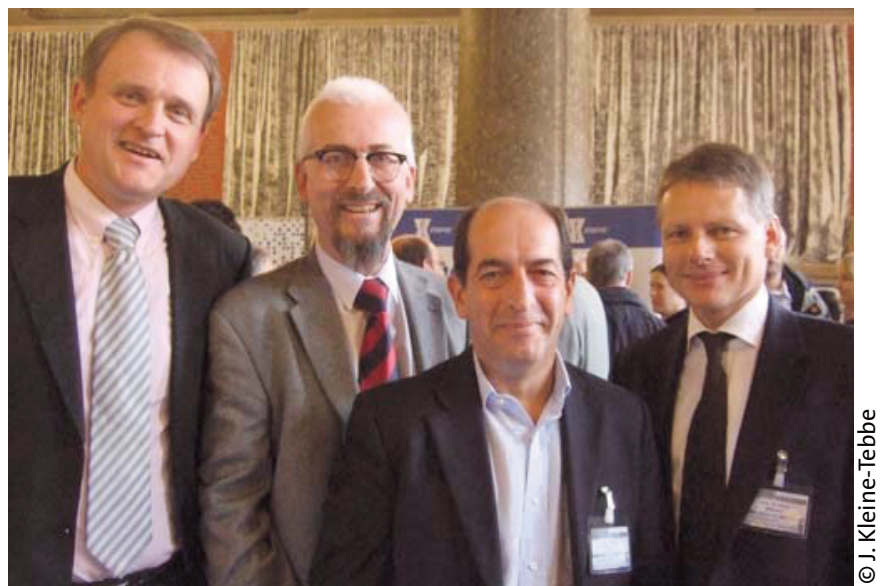

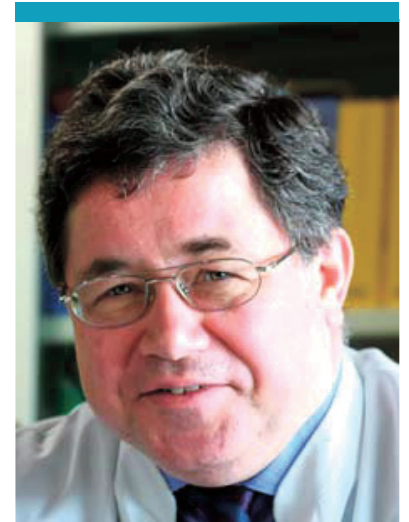

Prof. Dr. Hans F. Merk, Hautklinik der Medizinischen Fakultät, Universitätsklinikum der RWTH Aachen

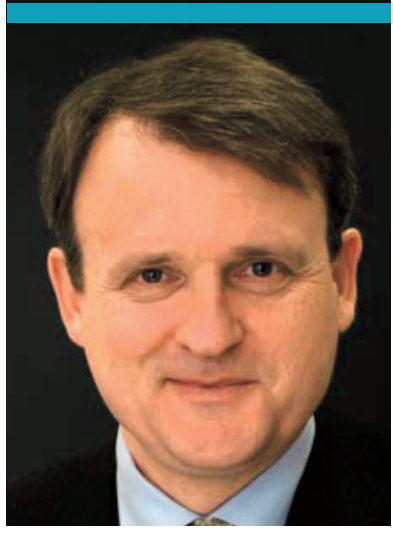

Prof. Dr. Thilo Jakob, AllergieAllergologie, UniversitätsHautklinik Freiburg abteilung \& Forschergruppe

eine Einführung in dieses neue und aufregende Gebiet. Vor dem Hintergrund der rasanten Entwicklung der molekularen Allergologie, die zunehmend auch für die Routinediagnostik zur Verfügung steht, soll die Fortbildungsserie die wesentlichen Kenntnisse über einzelne Aller- „Es ist uns ein großes Anliegen, gene, Allergengrup- dass hochspezialisiertes Detailpen und Allergen- wissen konsequent in brauchbare familien vermitteln. Information für den klinischen Wie findet man sich Alltag übersetzt wird." zurecht im Dickicht der Einzelkomponenten und was ist der wirkliche Mehrwert für den klinischen Alltag? Diese und ähnliche Fragen werden von Experten für Sie, die praktizierenden Allergologen, in kurzen und präzisen Übersichten dargestellt werden. Ein großes Anliegen ist es hierbei, dass hochspezialisiertes Detailwissen konsequent in brauchbare Information für den klinischen Alltag übersetzt wird.

Schließlich wirft der 5. Deutsche Allergiekongress immer kräftigere Schatten voraus, und das endgültige Programm ist unter www.allergiekongress.de einsehbar.

Anregende Lektüre wünschen
Prof. Dr. Thilo Jakob, PD Dr. Jörg Kleine-Tebbe und Prof. Dr. Markus Ollert (von links nach rechts) führen Sie ab dieser Ausgabe in ihrer neuen Serie in die Geheimnisse der molekularen Allergologie ein hier umringen sie ihren Meister „Mr. Allergome“ Dr. Adriano Mari aus Italien.
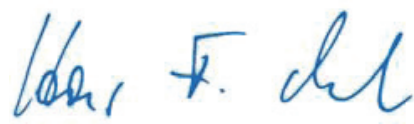

Prof. Dr. Hans F. Merk

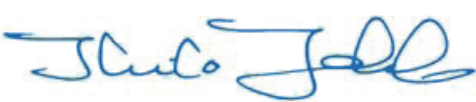

Prof. Dr. Thilo Jakob 